\begin{tabular}{l|l} 
Variants & $\begin{array}{l}\text { Variants } \\
\text { The Journal of the European Society for Textual } \\
\text { Scholarship }\end{array}$
\end{tabular}

12-13 | 2016

Varia

\title{
The Draft Manuscript as Material Foundation for Genetic Editing and Genetic Criticism
}

\section{Hans Walter Gabler}

\section{(2) OpenEdition \\ Journals}

\section{Electronic version}

URL: http://journals.openedition.org/variants/299

DOI: $10.4000 /$ variants.299

ISSN: 1879-6095

\section{Publisher}

European Society for Textual Scholarship

\section{Printed version}

Date of publication: 31 December 2016

Number of pages: 65-76

ISSN: 1573-3084

\section{Electronic reference}

Hans Walter Gabler, «The Draft Manuscript as Material Foundation for Genetic Editing and Genetic Criticism », Variants [Online], 12-13 | 2016, Online since 01 May 2017, connection on 02 May 2019. URL : http://journals.openedition.org/variants/299 ; DOI : 10.4000/variants.299 


\section{The Draft Manuscript as Material Foundation for Genetic Editing and Genetic Criticism}

Hans Walter Gabler

Abstract: As its point of departure, this essay makes a clear distinction between genetic criticism and genetic editing. For both, the material as well as visual referent is the manuscript, specifically the draft manuscript. An argument is developed in detail that the draft manuscript is a document sui generis, is essentially "autographic" and thus ontologically distinct from all other forms and modes of "manuscript". This brings into specific focus the editing of manuscripts. Defining manuscript editing (Handschriftenedition) as a distinct editorial mode leads to conceiving of the "manuscript edition" anew under premises of the "autographic" singularity of draft manuscript writing. The editorial way to realize manuscript editing is to transform both the document (materiality-and-writing) dimension and the text dimension of the draft manuscript into editorial presentation and representation. This is also a way to bring manuscript editing into partnership with genetic criticism. Realization and use of the manuscript edition is conceivable in the digital medium only. Keywords: Genetic edition, digital edition, genetic criticism, drafts, manuscripts, avant-texte, allographic text, textual transmission, editorial traditions, German literature.

There is an essential distinction to be made between "genetic criticism" and "genetic editing". ${ }^{1}$ Genetic criticism belongs to the range of discourses available to literary criticism. It is a mode of discourse to engage with a work of literature and the texts in which we meet the work, or the work meets us. The engagement always issues in discourse: commonly in the critic's free discoursing. Genetic criticism is thus an extension of the traditional modes of articulating literary criticism. Genetic editing, by contrast, is a mode of scholarly editing. As such, it is the answer in the pragmatics of editing to an extension of the spectrum of concerns of textual criticism through

A version of this article has appeared in Swedish (translated by Jon Viklund and Paula Henrikson from an earlier version of the underlying conference paper) under the title "Handskriften som en mötesplats för genetisk utgivning och genetisk kritik" in Kladd, utkast, avskrift. Studier av litterära tillkomstprocesser (Uppsala: Avdelningen för litteratursociologi, Uppsala universitet, 2015, pp. 21-32). 
an intensified observance of the traces of the conception and growth of writing and text itself in the materiality of documents.

Throughout the twentieth century, German textual criticism, for one, was at the fore-front of developing a genetic awareness of textual heritages, specifically such as could be traced back through authorial papers before publication of given works. From this grew a sub-genre of scholarly editions in print classed as Handschrifteneditionen (manuscript editions). Genetic criticism, by contrast, was an answer in France to the dominance of a structuralist approach in mid-century, and post-mid-century, in French literary criticism. Genetic critics of the French critical persuasion engage with the same categories of evidence of writing and the same classes of documents that preserve textual heritages as do the textual critics: with notes, prolegomena, drafts and their revisions, with proofs. But their analyses are not geared as were and are those of the traditional textual critic towards edited presentation of the textual materials. The genetic critic is all set, rather, on drawing critical conclusions from compositional, commonly pre-publication, material evidence. ${ }^{2}$ Engagement with such materials however is of a complexity far greater than is the reading of (and perhaps parallel note-taking from) texts in print. To order - even just as aid to future re-call - the thickets and snares of a draft manuscript, demands transcribing what one sees and believes to have recognized in and of its writing. Transcription became standard within French genetic criticism, but was at the same time understood as auxiliary to always also seeing (images of) the manuscript pages. Transcription and image in conjunction constituted, and constitute, together the genetic dossier. (The term gives the document perspective on what from the text perspective is named avant-texte.) They are requisite and suffice as reference base and working materials for the genetic critic. Seeing the French genetic critics relying on these

2 The current, portmanteau term for such material is avant-texte. To a nonFrench ear, it is a problematic term, since it suggests that what comes before the end of composition and before publication ("avant") is not yet "texte". This is correct only by a French understanding of texte, which is different (it seems) from the denotation of "text" in English or German. I have had occasion to discuss this slippage between denotations in my review of Daniel Ferrer, Logiques du brouillon. Modèles pour une critique génétique (Gabler 2011). Ferrer's book is the most elegant explication of the essence of French genetic criticism imaginable. 
working materials in what was for them their critical engagement with the genesis of text and work, the genetically aware scholarly editors from the German text-critical and editorial school, however, mistook the presentations supplementary to the genetically critical arguments for fully-fledged editions - as did eventually, too, their Anglo-American peers. Yet this turned out to be a fruitful misperception, since it stimulated the conceptualization of what a genetic edition might be and how it could be realized. The process of realizing such editions is, as meanwhile we know, fully predicated on the digital medium: the type of genetic edition striven for today is the digital genetic edition. What is essential to note, moreover, is that owing to the greater recognition that genetic criticism has come to enjoy as a form of critical inquiry, the demands it places on editing are distinctly broader than has been habitually the case in traditional textual criticism. This is entirely due to the growing awareness of the critical significance of the genetics of writing and text that genetic criticism has generated. It is from this premise that I wish to discuss the (in my view) singular status of the draft manuscript and to argue that the draft manuscript is even ontologically distinct from all other forms and modes of "manuscript".

\section{The draft manuscript}

Among the great variety of documents that materialize the texts of our cultures and civilizations, authorial draft manuscripts form a class of their own. What they carry and convey is never only text. Their significance lies equally in the tracing patterns of the writing they evidence. The materiality of their inscription finds expression not only in letters and numerals and their groupings into tokens of recognizable numbers, words, sentences - or, simply: into intelligible language. Essential to the inscriptions is equally their relative positioning on the writing surface, are the changes in ink or hands, or even the extra-textual authorial alerts or doodles signalling moments of non-writing or non-texting. Moreover, what acts of writing produce in draft documents does not (yet) automatically result in, or achieve, "text" in continuous linear readability. Draft manuscript writing is but incipiently a mode of writing for reading; it is never comprehensively, let alone exclusively text. The total evidence of draft writing cannot be reduced to just text. 
Text is the result of a writing-for-reading and is pre-conditioned by the rules and habits of reading: it advances linearly, two-dimensionally, from upper left-hand to bottom right-hand corner of a given material support, e.g. a page or sheet, and thence through a sequence of pages. But writing in draft documents is not so vectored. The prime function of draft documents, and the writing in them, is not to record text for reading, but to record, support and further engender composition. For the processes of composition, a writing space is not predetermined by expectations of linear text reading. What we encounter as writing in the pages of original draft documents, therefore, are the traces of how the document space was filled in the course of composition. Analysing and interpreting the traces, we gain a sense of how the writing gradually, that is in time, came into being in three visible dimensions as it spreads randomly over the document's two-dimensional surface and in many instances "rises above" that surface. The latter is the case for instance when traces in differently coloured ink or pencil run across the original inscription. At its best, the "reading" of a draft inscription amounts to a process of deciphering. This requires both a spatial comprehension and a comprehension of the temporal succession, the diachrony, of the inscription.

In draft manuscripts, consequently, the writing and its material support form an inseparable unity. To understand draft documents fully one must understand the interdependence of all their dimensions, the visual apprehension and the analytical and interpretive perception must always interact. Therefore, they must also always be conjointly communicated. This interaction requires presenting the documents visually through digital facsimiles and establishing around them a research environment in the digital medium. Presenting digital facsimiles may indeed be considered the primary concern and duty of scholarly manuscript editing today. What this requires under the premise of scholarship, at the same time, is to stabilize the communication of the manuscript images by means of transcriptions of the highest professional precision, even while always strictly understanding these as supplementary to the visual perception.

Writing, then, is not just inscribed on, but inseparably grafted into its material support. It is visually traceable within (rather than merely from) the document. Its essence lies in its appearance bodied 
forth in its materiality. The documents thus, quite simply, do not host or harbour texts, or "text", in the sense of linearly consecutive reading matter. Text as linear reading matter is always what is already copied off from the draft document, whether in acts of reading or acts of transcribing. In reproduction so initiated in reading or copying, and in subsequent potentially endless re-reproduction, text remains (or should ideally remain) essentially unaltered (in print or in digital files, say, or even in perfect, clean, manuscript fair copy). In Nelson Goodman's terminology, text so reproducible is "allographic" (Goodman 1968).

But writing, and the as yet only seeming text, in original draft manuscripts cannot be subsumed under the "allographic" category. Admittedly, writing in drafts commonly coalesces into text formation and the disposition of incipiently linear text segments over the manuscript space: such "texting", after all, is the main objective of drafting. Yet it is overridingly true that draft writing is thus grafted into, and hence consubstantial with, its material support. For original draft manuscripts it is true to say that document and inscription form an "autographic" unity. The term, again appropriated from Goodman (1968), refers not to the circumstance that drafts are produced - performed, as it were - in autograph, i.e. written in the author's hand. That they are commonly autographs in the bibliographical sense is their accidental quality. What makes them "autographic" in essence is their encompassing materiality: it is because in drafting the writing is grafted into unity with its material support that drafts qualify as "autographic" according to the "allograph"/"autograph" pairing. On grounds of this unity, draft documents are originals (in the manner, say, of paintings) and, by strength of their materiality, unique. Whereas fair copies and books exist materially mainly to make possible the reading of text, which consequently is always "allographically" detachable from any given material support, the materiality of draft manuscripts is as essential as is what is inscribed into it. How writing by common conventions, i.e. inscription of text, as well as interspersed random graphics are found to be spread over the space of a manuscript page is as significant as is the draft's readability. Hence, the textually intelligible content of manuscripts alone is never coequal to, and does not define, the manuscripts carrying it. Consequently, what is still persistently called "manuscript text" is 
not simply copyable, as text, out of the original manuscripts, the way text is always copyable from a fair copy into a typescript, or out of one book into the next, or from digital file to digital file. From drafts, rather, "text" can only be abstracted, which means it must be traced through the spatial and graphic patterning of the writing so as to separate it from its symbiotic unity with ink and paper. For this labour of extraction, it is necessary first visually to analyse the manuscript and then to correlate the resulting text to the document. In digital editions, the correlation will be self-evidently effected through linking the extracted transcription with a digital facsimile of the original.

Thus to make what ultimately amounts to an ontological distinction between, on the one hand, the material manifestation of writing in ("autographic") draft manuscripts for texts and of text in ("allographic") transmission through post-draft documents, on the other, is a fresh proposition that has only tentatively been gaining ground in recent years. What is helping to sharpen perceptions and focus definitions, as well as to stimulate the rethinking and reshaping of critical and editorial practice, is the exploration of original manuscripts by genetic criticism in France and elsewhere, as well as the migration of scholarly editing from the book medium to the digital medium. The draft manuscript provides the meeting ground for genetic editing and genetic criticism.

Writing, as I have argued, invades a draft's writing area spatially, and the traces it leaves in a draft are doubly vectored. In one respect, the writing serves composition, whereby language is composed of words and syntax that proleptically tend towards the readability of text. We customarily disentangle from a draft what appears readable, and so extract from it a linearly successive, albeit a frequently fragmented and incipient, text. Copied out by author, scribe or editor, text so discerned transcends the document into which it was first inscribed and thereby acquires its allographic nature. But in another respect, the writing traces in a draft, insofar as they are not just text, are indicators of the engendering impulses of and behind the composition. The spatial arrangement of the writing as such, as well as its manifold graphic features, give or have the potential to give - clues to the engendering impulses and thought processes that governed, or may have governed, the processes of text construction and composition. They form the 
core constituents of the draft as autograph, and its writing as autographic. The graphic and topographic features by which drafts, and only drafts, may be identified, never transcend the borders of the material document in which they reside; copying out the allographic text from the draft leaves them irretrievably behind. Thus, drafts feature a double reading order: the order of text and the order of material traces of text construction and composition. It is this singularity of the draft manuscript - autograph in production and autographic in nature - which, in its turn, categorizes manuscript editing (Handschriftenedition) as a mode of genetic scholarly editing of its own.

\section{The genetic trajectory of editing}

The idea of editing manuscripts is thus freshly brought into focus. The "manuscript edition" needs to be conceived anew with the aim of bringing out the "autographic" singularity of the draft manuscript. To define manuscript editing (Handschriftenedition) as indeed a distinct editorial mode, it is necessary, both in theory and in practice, to make a fundamental distinction between text editions and manuscript editions, as well as to take full measure of the difference between the book and the digital medium for organizing and presenting scholarly editions. Both "text" and "manuscript" modes of editing are familiar by name, and German Handschrifteneditionen in particular have in their practice attempted to convert the specificities of manuscripts into editorial presentation. Yet, if even just from technical necessity, these editions came out as books. ${ }^{3}$ However ingeniously they endeavoured to translate the processes of writing into symbolic coding, and (within affordable limits) provided facsimiles, they could only favour the text extracted from drafts, while under-representing, or eliding, the processual nature of the writing. Manuscript editions in book form basically assumed the guise and mode of text editions. Only today, as the digital medium is in the process of becoming - or perhaps has already become

3 In terms of a history of scholarly editing in the twentieth century, it may be said that the climactic end of the publication of Handschrifteneditionen in book form was reached with Hans Zeller's edition of the poems of Conrad Ferdinand Meyer (1963-1996) and Dieter Sattler's editing of the works of Friedrich Hölderlin (1975-2007). 
- the native medium for scholarly editions can text editions and manuscript editions be distinguished in kind and each realized specifically according to the nature of the object to be edited - and of the objective(s) editorially pursued. We are no longer reduced to merely thinking the categorical distinction, but are in a position to realize, or at least on the verge of realizing, the difference via distinct modes of editorial approach under the auspices, today, of the digital medium. In this, what is fundamental to the mode of the manuscript edition are new forms and modes of "taking in" the manuscript materially as document, and also as inscription manu scriptum - on that document.

\section{Manuscript writing under text and document perspectives}

It has been customary in editorial scholarship to record the physical properties of manuscripts - the paper, the size, the watermarks and such-like of the document carrying the manu scriptum - and to communicate all such observation in editorial prose. For the essential "editing of the manuscript", the convention has been to transcribe what is predominantly (if not exclusively) discernible as text from out of all that is found inscribed on, and into, the document. Transcription has always implied the lifting-off of the manuscript all writing acknowledged as text and transferring it to a fresh support. With the shift to the digital medium, such lifting-off and re-inscribing is naturally still a part of the operational practice. However, digital editorial projects that focus on manuscript sources have increasingly found themselves grappling with the problem that the lifting-off does not cleanly yield text alone. To put it another way, these projects have become aware of the considerable varieties of written traces that are present in the draft manuscript. These traces, moreover, are increasingly coming to be seen to carry meaning, i.e. they are interpretable, and thus they elucidate not only the text drafted, but also the writing process that leads up to the final text that results from the drafting. Of course, such traces had not, or not wholly, been overlooked by editors in the pre-digital era, but they were not considered relevant in the editorial process. Hence, print editions would omit anything that in the source documents was not readable as text or would at most (selectively) footnote or otherwise comment on instances of inextricable symbiosis between 
text-readable and non-text-readable traces in the draft writing. Editions midwifed into the digital medium, by contrast, must and can convey such information by combining re-inscription with digital re-visualization and so render the writing traces in draft manuscripts interpretable in their full complexity of interaction.

Transcription into the digital medium is organized by way of mark-up; and it is at the same time indeed argued through markup. The mark-up we have hitherto been conditioned and trained to employ, championed by the Text Encoding Initiative (TEI), has been predominantly "text mark-up". "Text", by its original understanding, was seen as the result of writing processes, and therefore foreshortened as being purely synchronic. Only very recently has the encoding repertoire of the TEI acquired the added dimension of guidelines and rules for genetic mark-up - a reorientation that finally acknowledges the essentially diachronic nature of writing and text. ${ }^{4}$ This has been, and is still being, designed to deal with all aspects of draft manuscripts, including those traces or patterns in the writing which cannot easily — or not all — be subsumed under the categories "texting" and text. It is the non-text-readable traces of the writing that constitute the image nature of the draft. If it is fundamental to the digital manuscript edition (as I said) to combine re-inscription with digital re-visualization, it is, over and above marked-up text transcription, equally essential to re-define the nature and function of the digitized manuscript image. The digital image in a digital edition is not merely illustrative (as was the facsimile image in a book). Just as the traces of text writing and non-text-writing interact in the material draft, so must they be rendered interactive in the digital edition. Hence, and in analogy to mark-up for the text writing, marking-up is required, too, for the digital image. This serves to identify and render retrievable the manuscript's multiple trace patterns and critically establishes their interconnection, as well as their connection with the markedup rendering of the manuscript's text content. The marking-up in its entirety constitutes the codification of all critical activity that goes into the editorial enterprise. Consequently, it is into the markup systems encompassing text writing and image that all critical judgement and decision is distilled which goes to shape the digital

4 See further the new TEI module for the encoding of Documents and Genetic Criticism at <http://www.tei-c.org/SIG/Manuscripts/genetic.html $>$. 
manuscript edition. The mark-up is where the edition's argument resides, so that from it may be extracted and visualized, for dynamically interactive communication at interface level, what the edition succeeds in offering.

The implementation of genetic mark-up in editorial projects is gaining ground. In Germany, it has been spear-headed by the genetic edition - calling itself a "genetisch-kritische HybridEdition" - of J. W. Goethe's Faust (2016). The editorial team's intense engagement over more than five years has been groundbreaking, and has developed manifold templates for future digital genetic editions to use, adapt or emulate. At the fundamental level of transcription and encoding through mark-up, the Faust edition has introduced a redoubled approach. The draft manuscript materials are twice marked-up, once from a document perspective and once from a text perspective. This approach recognizes the twice redoubled nature of the draft manuscript as a document that is both material in itself and that is materially inscribed; and whose inscription, moreover, is the material record both of the processes of the writing as such and of the writing as texting, resulting in text. $^{5}$

For my argument here, the Faust edition's double transcription practice has in turn a two-fold significance. The separation of a document perspective and a text perspective concurs, firstly, with our fresh definition of the draft manuscript as "autographic", and thus a document type sui generis where materiality, writing and text symbiotically merge. This re-doubled view of the draft manuscript thus, secondly, allows (and indeed requires), engaging critically with processes of composition and revision not only in the dimensions of texting and text alone, but also in their interdependence with the document materiality. So stated, this circumscribes anew the compass of manuscript exploration through genetic criticism.

Genetic manuscript editing, by contrast, is only beginning to assert itself and has not yet developed tested - let alone widely proven and accepted - practices for bringing the tenets and

5 Space does not permit me to go into the Frankfurt Faust edition's overall rationale, or even just its safe-guarding of correctness and accuracy in the complementary transcriptions. A comprehensive account of the edition is given in Bohnenkamp et al. (2012); see pp. 44-45 especially for an illustration of the application of the double mark-up approach. 
objectives of genetic criticism to the interface level of the digital medium. Designing modes of genetic editing and editions in terms both of organization and structure as well as of visualization and ports for analytic access, involves significant modifications and extensions of received editorial methodology, and indeed of the very concept of the "edition" as a product of scholarship. The Frankfurt digital edition of Goethe's Faust, remarkably highpowered in both scholarly expertise and in funding, has after close to six years of intense research and development only very recently managed to put its Beta version on the net. There, it joins, for instance, the Samuel Beckett Digital Manuscript Project $<$ http://www.beckettarchive.org>, today's flagship among editorial enterprises under sail on seas of genetic editing that are as yet only partially charted. ${ }^{6}$ Their compass settings, however, can be discerned as being for research sites whose hubs are digitally edited and organized text repositories, but which as research platforms are comprehensively sites for the dynamic and interactive acquisition, exchange and increase of knowledge and interpretative understanding. In terms of draft documents, they should be designed to present and communicate as well as render analysable the full range of the documents and the materials inscribed in these documents, including their semiotic and semantic features; and to do so, they should be powered for dynamic interactivity such as the digital medium allows. To engage with a digital manuscript edition would so permit not just to study, but actively to experience the genetic dynamics of manuscript writing.

\section{Bibliography}

Bohnenkamp, Anna, et al. 2012. "Perspektiven auf Goethes $>$ Faust $<$ : Werkstattbericht der historisch-kritischen Hybridedition". In Anna Bohnenkamp (ed.), Jahrbuch des Freien Deutschen Hochstifts. Göttingen: Wallstein Verlag, pp. 25-67.

Gabler, Hans Walter. 2011. Review of Logiques de brouillon, by Daniel Ferrer. Ecdotica, 8, pp. 276-80.

6 For a discussion of the Beckett Digital Manuscript Project's procedures of creating interface environments for digital manuscript editing, see Rehbein and Gabler (2013). 
Goethe, Johann Wolfgang. 2016. Faust : Historisch-kritische Edition. Eds. Anna Bohnenkamp et al. Frankfurt : no publisher. <http:// beta.faustedition.net/>.

Goodman, Nelson. 1968. Languages of Art: An Approach to a Theory of Symbols. Brighton: Harvester Press; Indianapolis: Bobbs-Merrill. Hölderlin, Friedrich. 1975-2007. Sämtliche Werke. 19 vols. Ed. Dieter Sattler. Frankfurt: Stroemfeld.

Meyer, Conrad Ferdinand. 1963-96. Sämtliche Werke: Gedichte. 7 vols. Ed. Hans Zeller. Bern: Benteli.

Rehbein, Malte with Hans Walter Gabler. 2013. “On Reading Environments for Genetic Editions". Scholarly and Research Communication 4(3), pp. 1-21, <http://src-online.ca/index.php/src/article/ viewFile/123/260> [accessed 8 October 2015] $>$. 